\title{
Epidemiology of microsporidia infection among apparently healthy subject and immunocompromised patients in Minna
}

\author{
Ubanwa E. ${ }^{1 \star}$, Omalu I. C. J. ${ }^{1}$, Olayemi I. K. ${ }^{1}$, Ejima, I. A. A. ${ }^{1}$ and Njoku, M. O. ${ }^{2}$ \\ ${ }^{1}$ Department of Animal Biology, Federal University of Technology, Niger state, Minna, Nigeria. \\ ${ }^{2}$ National Institution for Pharmaceutical Research and Development of Microbiology and Biotechnology, Idu Industrial \\ Area, Garki Abuja - Nigeria. \\ ${ }^{*}$ Corresponding author. Email: eubanwa@yahoo.com
}

Copyright @ 2019 Ubanwa et al. This article remains permanently open access under the terms of the Creative Commons Attribution License 4.0, which permits unrestricted use, distribution, and reproduction in any medium, provided the original work is properly cited.

Received 13th July, 2018; Accepted 13th August, 2018

\begin{abstract}
Microsporidia are obligate intracellular parasite that infect both vertebrate and invertebrate. In human, infection mostly focus on immunodeficiency and immunosuppressive individual. This study describes the prevalence, association of microsporidia infection with CD4 T Cell and risk factors associated with microsporidiosis among apparently health subject and immunocompromised individual in Minna, Niger state, Nigeria. Six hundred and Ninety-four (694) stools samples were collected and examined for microsporidia using Giemsa staining. Cytometer flow was used to determine CD4 T cell count. Pretest questionnaire was used to determine demographic, environmental hygiene, living condition and characteristics of the participants. Results showed $42(6.06 \%)$ of the participant with and without diarrhoeawere positive for microsporidia infection. Histogram were used to describe distribution of microsporidia infection across diseases state. With cytometer flow, 6 (33.3\%) among HIVIAIDS with $\leq 50 \mathrm{cell} / \mu$ l. Highest prevalence were recorded among age $\geq 15$ when compare with < 15 with $32(10.8 \%)$ and $10(7.47 \%)$, respectively. This study is first report of microsporidia in Niger state. Diagnose of microsporidia should be included in management of HIV/AIDS infection in Niger state.
\end{abstract}

Keywords: Cytometer, immunodeficiency, immunosuppressive, microsporidia.

\section{INTRODUCTION}

Microsporidia are opportunistic parasites that infect the microvillus border of intestinal track in a wide range invertebrate and vertebrates including human (ChacínBornilla, 2006). Infected individuals show a great range of spectrum of clinical symptoms however, pathogenicity of microsporidia species varies with the species of parasites involved, the age and immune status of the host (Sarfati et al., 2006).Gastrointestinal infections, especially those that lead to chronic diarrhoea, have been prominent positive to Enterocytozoon bieneusi since the advent of Human Immunodeficiency Virus/Acquire Immuno Deficiency Syndrome(HIV/AIDS) infection with profound and progressive effect on the cellular immune system in developing countries (Lores et al., 2002).
Studies have shown that 20 to $60 \%$ chronic malabsorption diarrhoea cases in HIV/AIDS patients are caused by microsporidia and $E$. bieneusi has been found in most cases, other includes $E$. intestinalis and $E$. hellem (Omalu et al., 2006). The parasite is commonly observed among HIV infected patients with low CD4 Lymphocyte count of less than $50 \mathrm{cell} / \mathrm{mm}^{3}$ (Likatavicius et al., 2010), although molecular epidemiology studies shown other group of individ ual at risk of asymptomatic includes organ recipients, immunocompromised patients, as well as immunocompetent individuals (Espern et al., 2007).

The pathways of microsporidia infections, modes, or routes of transmission and the knowledge of the epidemiology are still uncertain. Because microsporidia spores are released into the environment via stool, urine 
and respiratory secretion. Possible source of infection may be person or animal infected with microsporidia (Dwivedi et al., 2007). Waterborne transmission is one of main risk factor for intestinal diseases causing an important morbidity and mortality worldwide (Cotte et al., 2003; 2008). Domestic and wild animal have accumulation of pathogens through surface water that are capable of infecting human (Slodkowicz et al., 2006). With respect to some factor that predisposed man to microsporidia, it has been recognized as category $B$ biodefense agent on the National Institutes of Health list, and transmission of microsporidia spores is seriously considered by America agencies concerned with the quality of drinking water (Cheng et al., 2011).

Preventive efforts have been hindered by inadequate understanding of the importance of waterborne, personto- person, foodborne, and zoonotic transmission (Reinke et al., 2017). The study therefore examined the contribution of intestinal microsporidia to chronic diarrhea, associated risk factors contributed to infection, and relationship between CD4 cells and microsporidia infection in Minna.

\section{MATERIALS AND METHODS}

\section{Study area}

The studies were conducted in Minna, Niger state. Niger State lies on the $3.20^{\circ}$ East and longitude $11.30^{\circ}$ North with land mass covered area of 74,244 square kilometers, which is $8 \%$ of the total land area of Nigeria. With the merger, the land mass is about $10 \%$ of the total land area that is about $85 \%$ of the arable land. The 2006 population figure is 3, 950, 249. Soil types in Niger State are two: Ku soil and Ya soil. The Ku soil has little erosion hazards, while the Ya soil has better water holding capacity.

\section{Study sites}

Two study sites were chosen; General Hospital and Divine Mercy Hospital Dutsen Kura Kwari all in Minna, Niger state, Nigeria. These sites where chosen because of numerous subject and patient, General Hospital Minna is government hospital that runs free Doctor consultation and subsidize their treatment charges and also runs Heart to Heart center where Canceling and Testing of HIV/AIDS, Cluster Differential $4 \mathrm{~T}$ cell machine (CD4 T cell), DOTS and Gene X Pert Machine for Multi Drug-Resistance Tuberculosis (MRD-TB). Divine Mercy Hospital Dutsen Kura Kwari is part of Diocese Health Initiative (DHI) which is Faith Base Organization (FBO) that partner with Global forms to conduct house to house search of Tuberculosis in Minna and its environ also runs Heart to Heart Center where HIV/AIDs cancelling and testing is being done.

\section{Study design}

A cross-sectional and random sampling were carried out to determine the prevalence of Microsporidia infections, immune status among apparently healthy and immunocomprised individual in the study area. Participant in this study includes both hospitalized and out patients.

\section{Sample collection}

A total number of 1737 samples were collected from 702 participants, among the samples includes faeces, urine, nasal washing, vagina discharge and blood. Out of total number examined, 694 faeces, urine 332 , sputum 180, nasal washing 235, Vaginal swap 44, and blood 252 samples from 209 apparently healthy, HIV/AIDS 587, HIV - negative 169, TB/HIV/AIDS 316, TB/HIV - negative 159, Malaria/HIV/AIDS 129, Malaria/TB/HIV/AIDS 168. Blood were collected from each of the participants and control via antecubital vein with sterile syringes and needles, after disinfecting the puncture site with methylated spirit and discharge into Ethylene Diamine Tetra Acetate (EDTA) bottle for serological examination. Faeces, nasal washing and urine sample were collected using universal sample bottle label with participant hospital card number for easy identification. Sputum sample were collected using sputum container, while vagina swap was collected using a swap stick, Vagina swap were collected by a train female technologist after physical examination.

\section{Ethical statement}

The protocol for the study was approved by the Ethical Committee of the Federal University of Technology Minna, Divine Mercy Hospital, Dutsen Kura Gwari Minna and that of General Hospital Minna. All participants were given consent form prior to specimen collection.

\section{Samples collections and analysis}

A wide mouth screw capped container with scoop, labelled with individual hospital card number was distributed to each participants for collection of stool sample. The participants were instructed to scoop about 10 gram of stool sample using a provided scoop into the bottle container. In case of children, parents and guardians were instructed to monitor their children during sample collection to ensure they placed the sample in correct container.

Total number of Six hundred and ninety-four (694) stool samples were collected from October 2015 and September 2017 from both Apparently Health Subject and immunocompromised individuals from General Hospital Minna, and Divine Mercy Hospital Minna, Niger state. 


\section{Blood collection}

About $2 \mathrm{~m}$ of blood were collected from seventy-one (71) participants of individual through intra ventricular after dissing infecting the sight of puncture with mantling. The blood samples were discharged into EDTA bottle for further uses.

\section{Parasitological examination}

Microsporidia investigation, $0.5 \mathrm{~g}$ of stool sample was homogenized in ration 1:8 in distilled water, and filter in a $300 \mu \mathrm{m}$ pore mesh sieve and centrifuged at $1500 \mathrm{rpm}$ for $5 \mathrm{~m}$. Smear were made from sediment after discarding the supernatant fixed in methanol and stained with $10 \%$ Giemsa solution (Omalu et al., 2006) and examined at 1000x magnification (Oil emersion). The criteria used to define microsporidia positive was the presence of one or more pink - blue ovoid structure with a blue spore. The slide was re-confirmed by two technologists.

\section{CD4 T cells count}

For $\mathrm{CD}^{+}$cell count, FACScan cytometer flow (Becton Dickinson San Jose, California, USA) was used to determined $\mathrm{CD}^{+}{ }^{+}$cell count and analyses with sirnulet software (Becton Dickinson) included with FACScan following the manufacturer's instruction. The counter kit contains three reagents: CD4 PE antibody, CD4 buffer and sheath fluid reagents are popularly called $A, B$ and $C$ reagents respectively. $20 \mu \mathrm{l}$ of CD4 PE antibody aspirated are dispensed into rihosepartec test tube and $20 \mu \mathrm{l}$ of blood from EDTA bottle were aspirated and dispensed into the same rihosepartec test tube respectively. The mixture was gently mixed and incubate in dark cupboard for 15 minutes at room temperature. The mixed sample is gently shacked for every 5 minutes. After 15 minutes incubation, $800 \mu \mathrm{l}$ of CD4 buffer were aspirated and dispensed into the mixed incubated sample and plug counter. The cyflow machine separate $\mathrm{CD}^{+}$cells monocytes from noise. The test result is printed and save immediately. The CD4 dilution factor of 42 is calculated as follows: sample dilution $=20 \mu \mathrm{l}$, Antibody dilution $=20 \mu \mathrm{l}$, Volume of no lyse partec buffer $=800 \mu \mathrm{l}$

Dilution factor $=20 \mu \mathrm{l}+20 \mu \mathrm{l}+800 \mu \mathrm{l} / 20 \mu \mathrm{l}=42$.

\section{Questionnaire}

A structural questionnaire was developed in English and translated to their preferable language such as Nupe, Kpagi, and Hausa by trained assistant researchers and Laboratory technologists. Information of the participant was ascertained in person by asking question for demographic data (Age, gender, and education level). Environmental hygiene and living condition characteristics (i.e types of water supply, Latrine system, Sewage disposal system, and presence of domestic animal) of children who cannot provide information about their questionnaire where completed by the parents or the guardians.

\section{Data analyses}

Descriptive analyses percentage rate was used to describe the characteristic of the study population, including the prevalence of microsporidia. A chi-square test $\left(X^{2}\right)$ was used to test the association between the variables.

\section{RESULTS}

\section{Prevalence of Microsporidia infection in stools samples}

Out of 694 stool sample collected and diagnosis from both Apparently Health subject and immunocompromised individual, $42(6.06 \%)$ cases were positive from microsporidia infection of different species. Of these positive, $5(5.00 \%)$ are from Apparently Health subject, while HIV/AIDS, TB/HIV/AIDS, Mal/TB/HIV/AIDS sum up $37(6.22 \%)$ with and without diarrhea patients. 386 HIV/AIDS screened 12 were positive with prevalence rate of $3.10 \%$. Among HIV negative participant, there was no positive cases recorded in them. Among 84 TB/HIV/AIDS, $7(8.33 \%)$ positive cases were recorded while TB/HIV negative, 34 participants screened, 4 (11.6\%) were positive, which showed lowest prevalence rate acrossed the diseases state. For Mal/HIV/AIDS 26 participants screened, $8(30.8 \%)$ were observed and Mal/TB/HIV/AIDS 22 participants screened, $6(27.2 \%)$ were observed. Among all the diseases states, there was a significant difference of microsporidia prevalence acrossed disease state at $p<0.05$. Microsporidia specie differentiation using microscopic as Enterocytozoon bieneusi and Encephalitozoon intestinalis the spore of E. bieneusi were smaller than $E$. intestinalis and varied considerably in both shape and size (Table 1).

Histogram graph showed that E. bieneusi is highest specie of microsporidia among HIV/AIDS individuals while the lowest was among participants with TB/HIV negative. $E$. intestinalis was another microsporidia specie with highest prevalence among TB/HIV/AIDS and the lowest among TB/HIV negative, Mal/HIV/AIDS and Mal/TB/HIV/ AIDS respectively. Although there was no spore of microsporidia among HIV negative individual whose stand as control. The graph also indicates co-infection among 
Table 1. Prevalence of microsporidia in stool sample of apparently healthy subject and immune-compromised individual in Minna.

\begin{tabular}{lcc}
\hline Diseases state & No. Examined & No. +ve(\%) \\
\hline ApparentlyHealthy & 100 & $5(5.00)$ \\
HIV/AIDS & 386 & $12(3.10)$ \\
HIV - ve & 42 & $0(0.00)$ \\
TB/HIV/AIDS & 84 & $7(8.33)$ \\
TB/HIV - ve & 34 & $4(11.6)$ \\
Mal/HIVAIDS & 26 & $8(30.8)$ \\
Mal/TB/HIV/AIDS & 22 & $6(27.2)$ \\
Total & 694 & $42(6.06)$ \\
\hline
\end{tabular}

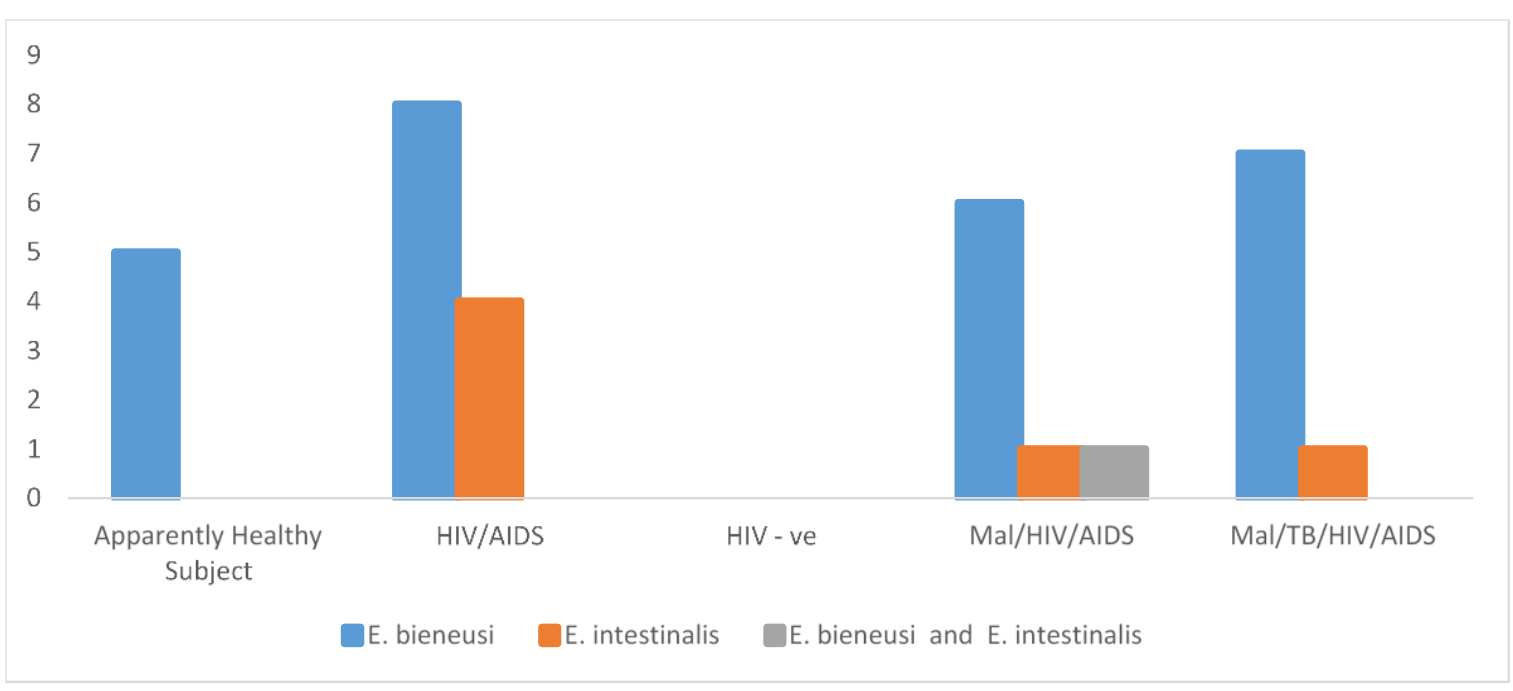

Figure 1. Showing distribution of Microsporidian species across diseases state.

HIV/AIDS, TB/HIV/AIDS, TB/HIV - ve, Mal/HIV/AIDS, $\mathrm{Mal} / \mathrm{TB} / \mathrm{HIV} / \mathrm{AIDS}$ individual respectively (Figure 1).

\section{CD4 T Lymphocytes}

$\mathrm{CD}^{+} \mathrm{T}$ cell count (Table 2) show that infections were higher among HIVIAIDS participant with $\leq 50 \mathrm{CD} 4^{+} \mathrm{T}$ cell count $6(33.3 \%)$ and lowest among HIV/AIDS participant with $>50 \mathrm{CD} 4^{+}$T cell count $2(3.77 \%)$.

\section{Associated risk factors for microsporidia and characteristic of population study}

A total number of 694 stool samples were collected randomly, out of which 468 participants partook in questionnaire. Of 468 questionnaires collected and analyzed, 294 of age $\geq 15$ recorded high prevalence with $32(10.8 \%)$ positive and 174 participants of age $<15$ recorded 10 positive cases with percentage rate of $7.47 \%$. $\mathrm{X}^{2}$ at $\mathrm{p}<0.05$ show no significant difference of microsporidia prevalence among ages. Among gender, 381 females have higher prevalence infection rate 29 $(7.61 \%)$ and 87 males, $13(14.9 \%)$, at $p<0.05$ there is significant difference of microsporidia prevalence between gender. Quarter of participants have low education level background, 113 < primary school recorded 12 positive cases with percentage infection rate of $10.6 \%$, while, 257 primary recorded 17 (6.6\%) positive and 98 participants who were $\geq$ secondary recorded 14 (14.2\%) positive, although there is no significant difference of microsporidia prevalence infection across educational level at $p<0.05$. However, most of them are farmer with no stable income. Source of water supply, pipe born 28 participants recorded $2(7.14 \%)$ positive, 86 participants who uses borehole recorded 4 positives with percentage rate $(4.65 \%)$, about half of the participant (294) uses wheel water, $16(5.44 \%)$ positive, 60 participant uses stream/river with 21 (35.0\%) positive, $x^{2}$ at $p<0.05$ show significant difference of 
Table 2. Number of CD4 Cells $/ \mu$ l of blood of patients with and without microsporidia.

\begin{tabular}{|c|c|c|c|c|c|c|c|}
\hline CD4 cells/ $\mu \mathrm{l}$ & $\begin{array}{c}\text { Subject } \\
\text { No. Exam } \\
\text { No.+ve(\%) }\end{array}$ & $\begin{array}{l}\text { HIV/AIDS No. } \\
\text { Exam No.+ } \\
\text { ve(\%) }\end{array}$ & $\begin{array}{c}\text { HIV - ve No. } \\
\text { Exam No.+ } \\
\text { ve(\%) }\end{array}$ & $\begin{array}{l}\text { TB/HIV/AID } \\
\text { S No. Exam } \\
\text { No.+ ve (\%) }\end{array}$ & $\begin{array}{l}\text { TB/HIV- ve } \\
\text { No. Exam } \\
\text { No.+ ve(\%) }\end{array}$ & $\begin{array}{c}\text { Mal/HIV/AIDS } \\
\text { No. Exam } \\
\text { No. + ve (\%) }\end{array}$ & $\begin{array}{c}\text { Mal/TB/HIV/AI } \\
\text { DS No. Exam } \\
\text { No. + ve (\%) }\end{array}$ \\
\hline$>50 \mathrm{cells} / \mu \mathrm{l}$ & - & $532(3.77)$ & $80(0.00)$ & 232 (8.69) & $30(0.00)$ & 261 (7.69) & $80(0.00)$ \\
\hline$\leq 50$ cells $/ \mu \mathrm{l}$ & - & 186 (33.3) & $50(0.00)$ & 124 (33.3) & $20(0.00)$ & $284(14.2)$ & $161(6.25)$ \\
\hline Total & & 718 (11.3) & $130(0.00)$ & $356(17.1)$ & $50(0.00)$ & $545(9.25)$ & $241(4.16)$ \\
\hline
\end{tabular}

prevalence of microsporidia infection among source of water. Defecation, 198 participant uses pit toilet recorded 17 positives with percentage infection rate of $8.58 \%, 86$ uses water system with 9 (10.4\%) positive was observed while 184 defecate in an open space recorded 17 (9.23\%), $X^{2}$ among defecation show no significant difference of microsporidia prevalence among participant $(p<0.05)$. Waste disposal was another criterion used, 96 uses government approved area for their waste disposal recorded $10(10.4 \%)$ positives and 210 disposes closed to house recorded higher prevalence of $25(11.9 \%)$, at $p<$ 0.05 there is no significant difference among them. Presence of domestic animal, 316 participants keep domestic animal recorded higher prevalence of microsporidia infection of $29(9.17 \%)$ while 152 who do not keep animal recorded $13(8.52 \%)$ positives cases, although there is no statistically significant difference of microsporidia prevalence among those who keep domestic animal at $p<0.05$. Our questionnaire review that more than half of the participant $67.5 \%$ kept domestic animal such as dogs, poultry, cats, rams and sheep (Table 3 ).

\section{DISCUSSION}

Human infections with microsporidia have been reported from all over the world, while majority of cases have involved HIV/AIDS -infected patients. Microsporidiosis prevalence in humans vary widely depending onthegeographical region, population studied and diagnostic methods used. Antibody to Enterocytozoon bieneusi, Encephalitozoon cuniculi and Encephalitozoon intestinalis serological test have been relied on to determine the prevalence of microsporidia infection before the era of AIDS. Seroprevalence result reviewed that $42 \%$ highest prevalence rate was recorded among homosexual men in Sweden (Hollister et al., 1991). Mmini to high prevalence of microsporidia infection have been reported among non-HIV infected subject using microscope studies and Polymerase chain reaction (PCR) technique among travelers to endemic areas $(3.6 \%-13 \%)$ (Lores et al., 2002), (1.7 - 18.4\%) (Aoun et al., 1997) with or without diarrhea in children and elderly peoples (17.2\%) (Didier et al., 2004). In this study, a total microsporidia prevalence was 42 with infection prevalence rate $6.06 \%$. This finding is not in line when compare with other study in other countries Malaysia 15\%, Spain 17\%, Thailand $14.9 \%$, Uganda 16.8\% and Czech Republic 15\% (Lores et al., 2002; Tumwine et al., 2002; Sak et al., 2011; Wanachiwanawin et al., 2002). Low prevalence rate in this study is in conformity with study conducted in Peru $8 \%$, Germany $\quad 0.7 \%$ and Tunisia $3.35 \%$ among immunocompetent individual respectively (Muller et al., 2001; Cama et al., 2007; Anane et al., 2011). In Nigeria, this finding is in line with other work conducted in different part of Nigeria Oladele et al. (2012) who conducted prevalence of microsporidia in Lagos state recorded $23.3 \%$, although this higher prevalence rate is due to the fact that research was conducted among indoor penitents. It also agrees with Omalu et al. (2006) who also investigate the seroprevalence of microsporidia infection among in and out patients in Kano state recorded percentage rate of $7.29 \%$. The highest rate of infection was among participants with Mal/HIV/AIDS $30.8 \%$ and HIV/AIDS $3.10 \%$. High prevalence rate may be as a result of protein energy malnutrition due to low immune status among the participants which contribute to more susceptible to microsporidia infection as it appears to be relationship between malnutrition and other enteric parasite infection.

Clinical aspect and consequence of microsporidia infection in human still pose several questions, but attempt have been made that peg it to immune status. In general, the clinical course of microsporidia really depends on the immune status and site of infection (Didier, 2005). In this study all the participants both subject and individual with CD4 lymphocytes counts of $<50$ cells $/ \mu$ had microsporidia infection which confirmed the fact that microsporidia infection is usually observed in patients with low CD4 cells. The low CD4 cell count is more rampart among HIV/AID group, hence, deficiency of their immune system among them. Nigeria is among developing countries where other tropical diseases causes immunocompromised below which intestinal microsporidia becomes clinically significant and sometimes even death. This explain the possibility of fewer individuals with low CD4 cells of $<50$ cells/ $\mu$ l. In healthy human such as travelers, self-limiting diarrhea with duration of about 2 to 3 weeks has been reported (Muller et al., 2001).

The present study statistically shows no significant difference in the prevalence of microsporidia according to 
Table 3. Some potential risk factors associated with microsporidia infection in Minna.

\begin{tabular}{|c|c|c|c|c|c|}
\hline Variable & No. Exam. & No. +ve & Infection (\%) & $95 \% \mathrm{CL}$ & P. value \\
\hline \multicolumn{6}{|l|}{ Age } \\
\hline$<15$ & 174 & 10 & 7.47 & \multirow{2}{*}{3.841} & \multirow{2}{*}{1.464} \\
\hline$\geq 15$ & 294 & 32 & 10.8 & & \\
\hline \multicolumn{6}{|l|}{ Gender } \\
\hline Male & 87 & 13 & 18.3 & \multirow{2}{*}{3.841} & \multirow{2}{*}{9.468} \\
\hline Female & 381 & 29 & 7.61 & & \\
\hline \multicolumn{6}{|l|}{ Educational Level } \\
\hline$<$ Primary & 113 & 12 & 10.6 & \multirow{3}{*}{5.991} & \multirow{3}{*}{5.417} \\
\hline Primary & 257 & 17 & 7.00 & & \\
\hline$\geq$ Secondary & 98 & 14 & 15.31 & & \\
\hline \multicolumn{6}{|l|}{ Source of Water } \\
\hline Pipe born & 28 & 2 & 7.14 & \multirow{4}{*}{7.815} & \multirow{4}{*}{51.247} \\
\hline Boreholes & 86 & 4 & 4.65 & & \\
\hline Wheel & 294 & 16 & 6.12 & & \\
\hline Stream/River & 60 & 21 & 35.0 & & \\
\hline \multicolumn{6}{|l|}{ Defecation } \\
\hline Pit toilet & 198 & 17 & 19 & \multirow{3}{*}{5.99} & \multirow{3}{*}{0.099} \\
\hline Water system & 86 & 09 & 09 & & \\
\hline Bushes & 184 & 17 & 17 & & \\
\hline \multicolumn{6}{|l|}{ Waste disposal } \\
\hline Government approved area & 96 & 10 & 10.41 & \multirow{2}{*}{3.841} & \multirow{2}{*}{0.291} \\
\hline Close to house & 210 & 25 & 12.85 & & \\
\hline \multicolumn{6}{|l|}{ Present of domestic animal } \\
\hline Yes & 316 & 29 & 38 & \multirow{2}{*}{3.841} & \multirow{2}{*}{0.639} \\
\hline No & 152 & 13 & 7 & & \\
\hline
\end{tabular}

gender of participants and this is in conformity with study conducted in Malayasia by Anuar et al. (2013). With respect to age in this study, 15 years and above recorded high prevalence of microsporidia infection when compare with less than 15 years. This is in line with the research conducted in Czech Republic among more than 50 years old participants of immunocompromised individuals and foreign student who had 34 to $56 \%$ of prevalence rate (Sak et al., 2011). Norhayati et al. (2008) reported $57.2 \%$ of microsporidia infection among adult of 25 and above in Malaysia. The high prevalence of microsporidia among this age is far from the activities that predisposed their age to microsporidia infection compare with less than 15 years. The observation that microsporidia are ubiquitous in nature suggest that several modes of transmission and source exist for human infection which make possibility of human to human transmission. Didier et al. (2004), Bern et al. (2005) and Anuar et al. (2013) who conducted several study on microsporidia transmission using animal mode proved that the same animal species could be transmitted between human through the same pathway as in animal. Globalization of food, faster trans-porttation of food, increasing travel of consumer and change in patterns in food consumption have been tag as a vehicle of microsporidia infection transmission (Orlandi et al., 2002). Research conducted in Sweden showed that cucumber slices in both cheese sandwiches and salad were the most probable root of transmission for food borne outbreak associated with E. bieneusi (Decraene et al., 2012).

\section{Conclusion}

The results provide new data on epidemiology of microsporidia infection among apparently healthy subject and immunocompromised in Minna, which posed question 
of if this finding truly represent infection resulting in shedding of parasites or ingested parasite passed through the gastrointestinal track without establishing an infection. The study on risk factors associated with microsporidia have helped in identifying the source of the infection in the environment that pose a risk for transmission and this will help in designing preventive strategies. More importantly, it has helped to determine the dynamic of microsporidia levels and virulence protein factors.

\section{CONFLICT OF INTEREST}

The authors declare that they have no conflict of interest.

\section{REFERENCE}

Anane, S., Kaouech, E., Belhadj, S., Abdelmalek, R., \& Ammari, L. (2011). Identification of Enterocytozoon bieneusi by PCR in stools of Tunisian immunocompromised patients. Pathology Biology, 59, 234-239.

Anuar, T. S., Al-Mekhlafi, H. M., Salleh, F. M., \& Moktar, N. (2013). New insights of microsporidial infection among asymptomatic aboriginal population in Malaysia. PloS one, 8(8), e71870.

Aoun, K., Barbouche, R., Bouratbine, A., Bejaoui, M., \& Dellagi, K. (1997). Microsporidiosis intestinalis chez des enfants attaints de deficits immunitaires primitives. Parasite, 4, 386387.

Bern, C., Kawai, V., Vargas, D., Rabke-Verani, J., \& Williamson, J. (2005). The epidemiology of intestinal microsporidiosis in patients with HIV/AIDS in Lima, Peru. Journal Infection Diseases, 191, 1658-1664.

Cama, V. A., Pearson, J., Cabrera, L., Pacheco, L., \& Gilman, R. (2007). Transmission of Enterocytozoon bieneusi between a child and guinea pigs. Journal of Clinical Microbiology, 45, 2708-2710.

Chacín-Bornilla, L. (2006). Microsporidiosis: an emerging and opportunistic infection. Investigation Clinical, 47(2), 105-107.

Cheng, H. W., Lucy, F. E., Graczyk, T. K., Broaders, M. A., \& Mastitsky, S. E. (2011). Municipal wastewater treatment plants as removal systems and environment sources of humanvirulent microsporidian spores. Parasitology Research, 109(3), 595-603.

Cotte, L., Rabodonirina, M., \& Chapuis, F. (1999). Waterborne outbreak of intestinal microsporidiosis in persons with and without human immunodeficiency virus infection. Journal of Infected Diseases, 180(6), 2003-2008.

Decraene, V., Lebbad, M., Botero-Kleiven, S., Gustavsson, A. M. \& Lofdahl, M. (2012). First reported foodborne outbreak associated with microsporidia, Sweden, October 2009. Epidemiology Infection 140, 519-527.

Didier, E. S. (2005). Microsporidiosis: an emerging and opportunistic infection in humans and animals. Actar of Tropical Diseases, 94, 61-76.

Didier, E. S., Stovall, M. E., Green, L. C., Brindley, P. J., \& Sestak, K. (2004). Epidemiology of microsporidiosis: sources and modes of transmission. Veterinary Parasitology, 126, 145166
Dwivedi, K. K., Prasad, G., Saini, S., Mahajan, S., Lal, S., \& Baveja, U. K. (2007). Enteric opportunistic parasites among HIV infected individuals: associated risk factors and immune status. Journal of Infection Diseases, 60(2-3), 76-81.

Espern, A., Morio, F., \& Miegeville, M. (2007). Molecular study of microsporidiosis due to Enterocytozoon bieneusi and Encephalitozoon intestinalis among human immunodeficiency virus-infected patients from two geographical areas: Niamey, Niger, and Hanoi, Vietnam. Journal Clinical Microbiology, 45(9), 2999-3002.

Hollister, W. S., Canning, E. U., \& Willcox, A. (1991). Evidence for wide spread occurrence of antibodies to Encephalitozoon cuniculi (Microspora) in man provided by ELISA and other serological tests. Parasitology, 102, 33-43.

Likatavicius, G., \& Van de Laar, M. J. (2010). HIV and AIDS in the European Union, 2009. European Surveillances, 15(48), 19737.

Lores, B., Lopez-Miragaya, I., Arias, C., \& Fenoy, S., Torres. (2002). Intestinal microsporidiosis due to Enterocytozoon bieneusi in elderly human immunodeficiency virus-negative patients from Vigo, Spain. Clinical of Infection Diseases, 34, 918-921.

Muller, A., Bialek, R., Kamper, A., Fatkenheuer, G., \& Salzberger, B. (2001). Detection of microsporidia in travelers with diarrhea. Journal of Clinical Microbiology, 39, 1630-1632.

Norhayati, M., Azlin, M., Al-Mekhlafi, M. H., Anisah, N., Aini, U. N., Fatmah, M. S., \& Rozlida, A. R. (2008). A preliminary study on the prevalence of intestinal microsporidiosis in patients with and without gastrointestinal symptoms in Malaysia. Transactions of the Royal Society of Tropical Medicine and Hygiene, 102(12), 1274-1278.

Omalu, D., Duhlinska, G., Anyanwu, V., Pam, P., \& Inyama (2006). Seroprevalence of Microsporidiosis in Immunocompromised Patients in Kano-Nigeria. The Internet Journal of Parasitic Diseases, 1(2).

Orlandi, P. A., Chu, D. T., Bier, J. W., \& Jackson, G. J. (2002). Parasites and the food supply. Food Technology, 56, 72-81.

Sak, B., Kvac, M., Kuceroza, Z., Kvetonova, D., \& Sakova, K. (2011). Latent microsporidial infection in immunocompetent individuals - A longitudinal study. PLoS Neglected Tropical Diseases, 5, e1162.

Sarfati, C., Bourgeois, A., \& Menotti, J. (2006). Prevalence of intestinal parasites including microsporidia in human immunodeficiency virus-infected adults in Cameroon: a crosssectional study. Am. J. Trop. Med. Hyg., 74(1), 162-164.

Slodkowicz-Kowalska, A., Graczyk, T. K., \& Tamang, L. (2006). Microsporidian species known to infect humans are present in aquatic birds: implications for transmission via water? Applied Environmental Microbiology;72(7), 4540-4544.

Tumwine, J. K., Kekitiinwa, A., Nabukeera, N., Akiyoshi, D. E., \& Buckholt, M. A. (2002). Enterocytozoon bieneusi among children with diarrhea attending Mulago Hospital in Uganda. The American journal of Tropical Medicine and Hygiene, 67(3), 299-303.

Wanachiwanawin, D., Chokephaibulkit, K., Lertlaituan, P., Ongrotchanakun, J., Chinabut, P., \& Thakerngpol, K. (2002). Intestinal microsporidiosis in HIV-infected children with diarrhea. Southeast Asian Journal of Tropical Medicine and Public Health, 33(2), 241-245. 